\title{
INFLUENCE OF PROBIOTIC SUPPLEMENTATION ON CLIMACTERIC SYMPTOMS IN MENOPAUSAL WOMEN-A MINI REVIEW
}

\author{
BHAGAVATHI SUNDARAM SIVAMARUTHI, PERIYANAINA KESIKA, CHAIYAVAT CHAIYASUT*
}

\author{
Innovation Center for Holistic Health, Nutraceuticals, and Cosmeceuticals, Faculty of Pharmacy, Chiang Mai University, Chiang Mai 50200, \\ Thailand \\ Email: chaiyavat@gmail.com
}

Received: 21 Feb 2018, Revised and Accepted: 04 Sep 2018

\begin{abstract}
Menopause (MP) is a natural physiological event of woman's life and is defined as the absence of menstrual periods for at least twelve months and loss of function of ovarian. The common symptoms of MP are irregular vaginal bleeding, hot flushes especially in head and chest, night sweats, insomnia, vaginal and urinary symptoms, cognitive dysfunction, increased cancer risk, osteopenia, high blood pressure, diabetes, and cardiovascular diseases. Microbiome has been associated with several health benefits. Probiotic supplementation helps to enhance the quality of microbiome thereby confers the health benefits to the host system. The microbiome, hormone (estrogen) changes, and probiotic intervention are related to the health status of the female reproductive system. The vaginal microbiome (VM) play a critical role in female reproductive health and MP, which can be greatly influenced by probiotics, and other medicine especially antibiotics and hormone therapy. The role of VM in supporting vaginal health is not clear and debatable. Understanding the role of vaginal Lactobacillus could expose the pathogenesis of vaginal dysbiosis, which helps to improve diagnostic and therapeutic strategies for several dysbiosis associated health issues and menopause-related symptoms. Recent studies suggested that the intervention of probiotic preparation with or without nutraceutical formulation (mostly with isoflavones) improve the health status of menopausal women. The mechanism of probiotics mediated health improvement in menopausal women is not yet described clearly. Several controversies are there on the link between probiotic, gut microbiota, vaginal microbiota, and estrogen deficit. The present review summarizes the influence of probiotic supplementation on climacteric symptoms in menopausal women. The literature search was made in Scopus, Google Scholar, PubMed using the keywords "probiotics" and "menopause". The documents were carefully checked for the relevance to the current manuscript, and the selection was made without any restriction in the year of publication.
\end{abstract}

Keywords: Probiotics, Estrogen, Menopause, Vaginal microbiome, Climacteric symptoms

(C) 2018 The Authors. Published by Innovare Academic Sciences Pvt Ltd. This is an open access article under the CC BY license (http://creativecommons.org/licenses/by/4.0/) DOI: http://dx.doi.org/10.22159/ijap.2018v10i6.29156

\section{INTRODUCTION}

Menopause (MP) is a natural physiological event of woman's life and is defined as the absence of menstrual periods for at least twelve months and loss of function of ovarian. MP is not a rapid biological event but is a relatively slow biological process. The age of MP varies (46-52 y) among the people, which greatly depends on the socioeconomic status, personal health care, and food habits. There is no unswerving test to predict the onset of MP. Moreover, MP can't be predictable with the time of initial mensural period. The symptoms and the experience of the perimenopausal transition period differ for each woman $[1,2]$.

The common symptoms of MP are irregular vaginal bleeding, hot flushes especially in head and chest (about 85\% of woman experiencing the hot flushes), night sweats, insomnia, vaginal symptoms (dryness, irritation, dyspareunia, and infections), urinary symptoms (frequent urination, urinary incontinence), cognitive dysfunction, physical changes, restlessness, muscle and joint pain, and MP also associated with increased cancer risk, osteopenia, high blood pressure, diabetes, and cardiovascular diseases. The symptoms are not common to all woman. Some people do not feel any or some of the symptoms during their MP [3-5].

The hormone changes or deficiency is the main cause of MP. Thus, hormone replacement therapy (HRT) is the primary treatment method to nullify or reduce the MP symptoms and to prevent the development of heart diseases and osteoporosis. The mode of administration, dose, and combination of the hormone are the key factors that affect the efficiency of the treatment and help to reduce the adverse side effects. Oral administration therapy was less effective compared to transdermal estrogen therapy [5].

Though HRT has beneficial effects, some of the controversial side effects were reported. The contentious HRT increased the risk of cancer development, thromboembolism, and cardiovascular consequences. There was no general treatment procedure, and HRT should be customized for each woman [6-8]. Moreover, many women seek alternative treatments other than HRT, when there are several health risks and uncertainty on reported benefits of HRT [6].

The serotonin-norepinephrine reuptake inhibitor and selective serotonin reuptake inhibitor were used to treat the hot flushes. These inhibitors help to improve vasomotor symptoms and sleep quality [9]. The phytoestrogens (PE) are phenolic compounds present in plants with mammalian estrogenic activity. PE binds to estrogen receptors and endorses either agonist or antagonist functions [10].

Probiotics are living microbes when administered in an adequate amount, confers beneficial effects in the host health. Commonly, lactic acid bacteria (LAB) are considered as probiotics, and beneficial impact of the probiotics is highly associated with an individual's health status, age, and lifestyle [11]. Probiotic strains were reported for several health aids and applications [11-23]. Changes in the gut microbiome influence the several physiological and biological process. The microbiome changes during estrogen deficiency, characteristics of MP, critically affects the MP symptoms and facilitates the development of illness like inflammatory diseases. The supplementation of probiotics significantly influences the gut microbiome of an individual [24].

Since the alternative therapies for MP with phytoestrogen and herbal products have been detailed previously by Borrelli and Ernst [25]. The current review narrates the probiotic based alternative treatment for MP and its impact on climacteric symptoms of menopausal women. The literature search was made in Scopus, Google Scholar, PubMed using the keywords "probiotics" and "menopause". The documents were carefully checked for the relevance to the current review, and the selection was made without any restriction in the year of publication.

\section{Microbiome of women}

The microbiome is unique for every individual to some extent. The gut microbiome plays an essential role in almost all biological events 
and cognitive functions. Subsequently, microbiome might possibly have a role in making healthy offspring moreover in persuading the general health status of an individual. The microbiome of a woman differs from man. The vaginal microbiome (VM) is influenced by several factors like menses, vaginal discharge, and sperm. VM greatly influences the health status of offspring. Lactobacillus spp. (especially Lactobacillus crispatus, L. gasseri, L. iners, and L. jensenii) are the dominant bacterial species present in VM of healthy women, and any alteration in the composition of VM leads to several adverse conditions like preterm birth, infertility, inflammatory and high risk of sexually transmitted diseases. Finally, it affects the quality of life [26-28]. Atopobium, Prevotella, Peptoniphilus, Dialister, Megasphaera, Gardnerella are some of the leading non-Lactobacillus microbial community residing in the urogenital tract of women [26].

The role of VM in sustaining vaginal health is not clear and controversial. Understanding the role of vaginal Lactobacillus could uncover the pathogenesis of vaginal dysbiosis, which helps to refine diagnostic and therapeutic strategies for several dysbiosis associated health issues and to diminish or manage the menopauserelated symptoms [29].

The VM composition differs in post-menopausal women when compared with premenopausal women, particularity the Lactobacillus content. The VM is extremely affected by the HRT [30-32]. Menopause decreases a load of Lactobacillus in VM, and also affects the diversity of microbes. Age, menstruation, hormone levels, intercourse, other lifestyle habits like smoking, hygiene have an impact on the bacterial community of a woman [33,34]. The description of the VM in different stages in a woman's life is multifaceted [35].

The dramatic change in VM could be noted at the time of puberty when hormone (estrogen) and glycogen levels increase [36]. The increased level of estrogen and glycogen facilitates or promote the growth of Lactobacillus, and it is known that the high level of glycogen is maintained during the fertile period of a woman and further decline in its level during menopause. Lactobacillus protects the vaginal area from pathogenic colonization by creating the acidic microenvironment, but an overgrowth of microaerophilic bacteria cause distress, itching, and foul-smelling discharge [37, 38]. Several studies suggested that diversity of Lactobacillus spp. and its richness has been decreased during or after menopause [36].

\section{Probiotics and menopause}

The postmenopausal women with the significantly high Nugent score (between 4 to 6) were screened and selected for the study. The Nugent scoring is an unbiased, semi-quantitative evaluation (microbial content) of vaginal secretion. The subjects were randomly divided into two groups and supplemented with either probiotic (lyophilized L. reuteri RC-14 and L. rhamnosus GR-1 along with sodium alginate; $2.5 \times 10^{9} \mathrm{CFU}$ each) or placebo (lactose) for fourteen days. After the intervention, vaginal swabs were collected and further subjected to Nugent scoring. The results showed that about $60 \%$ of women who received probiotic supplement had a reduction in their Nugent score from the baseline when compared to that of the placebo group. About three grade reduction was observed among the probiotic group, which indicates the significant improvement in the host health. The results suggested that the oral supplementation of probiotics help to restore the normal flora of the vagina [39].
About 2044 women (40-65 y) were supplemented with a mixture of soybean extract (contains genistein and daidzein; $30 \mathrm{mg}$ each), $L$. sporogenes (500 million spores), $5 \mu \mathrm{g}$ of vitamin D and $141 \mathrm{mg}$ of calcium for six months and the changes in climacteric symptoms were assessed by questionnaire. The changes were noted by gynecologists and self-assessment. The results suggested that the soybean extract with probiotic supplementation significantly improved the climacteric symptoms and sexuality [40].

A double-blind, randomized, placebo-controlled study was conducted with postmenopausal women with vaginal atrophy symptoms to know the impact of supplementation of Gynoflor ${ }^{\circledR}$ vaginal tablets (a blend of $L$. acidophilus KS400 and estriol $0.03 \mathrm{mg}$ ). The supplement was provided for $12 \mathrm{~d}$ for initial treatment and 2 tablets per week for $12 \mathrm{w}$ to maintain the effects. Vaginal maturation index (VMI) was changed positively in the treatment group (35.2\%) when compared to placebo (9.9\%). The study proved that Gynoflor ${ }^{\circledR}$ is effective in reducing vaginal atrophy symptoms and improved the VMI [41].

The ovariectomized mouse was supplemented with L. reuteri ATCC PTA 6475 via oral gavage $\left(1 \times 10^{9} \mathrm{CFU} / \mathrm{ml}\right.$ trice per day $)$ and through drinking water $\left(1.5 \times 10^{8} \mathrm{CFU} / \mathrm{ml}\right)$ for four weeks. The probiotic supplementation significantly reduced the bone resorption and osteoclastogenesis. The increase in CD4+T-lymphocytes has been reduced and thereby L. reuteri directly repressed osteoclastogenesis, and probiotic intervention altered the gut microbiome of the experimental mouse, especially Clostridiales was increased in the treated mouse. The results suggested that supplementation of $L$. reuteri suppress the post-menopausal bone loss [42].

Symptomatic postmenopausal women were treated with probiotic (B. breve B3 ATCC 15700; 1 trillion CFU) and nutraceutical formula (80 mg of soy isoflavones, $50 \mathrm{mg}$ of Angelica sinensis extract, $200 \mathrm{mg}$ of Morus alba leaf extract, and $56.25 \mathrm{mg}$ of magnesium) for $4 \mathrm{w}$ or probiotic and placebo or vice versa. The menopause rating scale (MRS) score was reduced, and a significant reduction in triglycerides, LDL, and increase in HDL was observed in the probiotic-treated group. The intervention of probiotic and nutraceutical formula improved the MRS score and risk of cardiovascular diseases [43]. Peri-menopausal women subjects were supplemented with isoflavones and probiotics $(34 \mathrm{mg} / \mathrm{d}$ isoflavones; probiotic combinations and dosage were not revealed in the study) for $12 \mathrm{w}$. The hot flush frequency (HFF), hot flush intensity, selfreported HFF, and hot flush severity, plasma lipids and blood pressure were measured. The results suggested that moderate intervention of red clover isoflavone and probiotics significantly reduced the self-reported vasomotor symptoms [44].

Postmenopausal breast cancer patients receiving chemotherapy (with vaginal atrophy and altered microbiota) were treated with probiotics (a mixture of $1 \times 10^{9} \mathrm{CFU}$ of L. crispatus LbV 88, $1 \times 10^{9} \mathrm{CFU}$ of $L$. rhamnosus LbV 96, $0.2 \times 10^{9} \mathrm{CFU}$ of $L$. ensenii LbV 116 and $0.3 \times 10^{9} \mathrm{CFU}$ of L. gasseri LbV 150N) twice daily for two weeks. After treatment, changes in the vaginal microbiota and Nugent score were reexamined and compared with baseline. The results suggested that probiotic intervention significantly reduced the Nugent score in the probiotic-treated group when compared to that of the placebo. The vaginal microbiota also altered positively in probiotic-treated women. The study proved that probiotic supplementation helps to regain the normal vaginal flora in women receiving chemotherapy for cancer [45].

Table 1: The influence of probiotic supplementation on the consequences of menopause

\begin{tabular}{|c|c|c|c|c|c|c|}
\hline $\begin{array}{l}\text { S. } \\
\text { No. }\end{array}$ & Subjects & Intervention & Dose & Duration & Findings & Ref. \\
\hline 1 & $\begin{array}{l}\text { Postmenopausal women } \\
\text { (72 subjects) }\end{array}$ & $\begin{array}{l}\text { L. rhamnosus GR-1 and } L \text {. } \\
\text { reuteri } \mathrm{RC}-14\end{array}$ & $\begin{array}{l}2.5 \times 10^{9} \mathrm{CFU} \\
\text { each }\end{array}$ & $14 \mathrm{~d}$ & $\begin{array}{l}\text { Nugent score was reduced, and } \\
\text { health status improved } \\
\text { significantly. }\end{array}$ & [39] \\
\hline 2 & Women (2044 subjects) & $\begin{array}{l}\text { Soy extract (genistein and } \\
\text { daidzein; } 30 \text { mg each), } \\
\text { L. sporogenes, calcium (141 } \\
\text { mg) and vitamin D ( } 5 \mu \mathrm{g}) \text {. }\end{array}$ & $\begin{array}{l}500 \text { million } \\
\text { spores }\end{array}$ & $6 \mathrm{mo}$ & $\begin{array}{l}\text { Improved the climacteric } \\
\text { symptoms and sexuality }\end{array}$ & [40] \\
\hline 3 & $\begin{array}{l}\text { Postmenopausal women } \\
\text { with vaginal atrophy }\end{array}$ & $\begin{array}{l}\text { L. acidophilus KS400 and } \\
\text { estriol } 0.03 \mathrm{mg} \text { (Gynoflor }(\text { ) }\end{array}$ & - & $\begin{array}{l}\text { Single tablet for } \\
12 \mathrm{~d} \text { followed by }\end{array}$ & $\begin{array}{l}\text { Gynoflor } ₫ \text { improved VMI after } \\
\text { the 12-day initial therapy, and }\end{array}$ & [41] \\
\hline
\end{tabular}




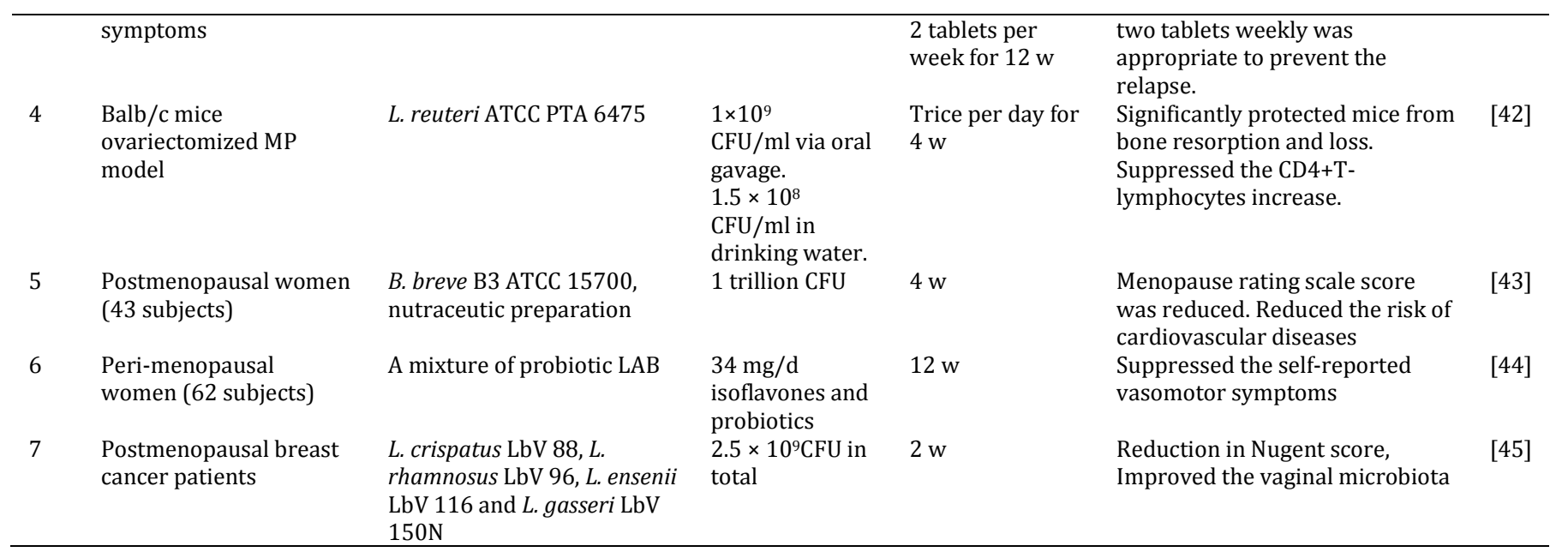

\section{CONCLUSION}

Generally, probiotic supplementation improved the health status of gastrointestinal (GI) system, and it has been proved by several clinical and human studies. Recently, the health benefits of probiotic were beyond the GI and its associated system such as anti-aging, anti-inflammation, improved the cognitive decline, antihypertension, anti-hypercholesterolemia, etc. The role of probiotic to manage the postmenopausal disorders and to control the climacteric symptoms is the recent subject of interest for several researchers [46]. The well-planned, placebo-controlled clinical studies on the health benefits of probiotics in menopausal women are very limited (table 1). The reports clearly suggested that the intervention of optimum level of probiotic supplementation along with some nutraceuticals improved the climacteric symptoms and vaginal health status by altering the microbiota. Several studies recommend the isoflavones supplementation to treat symptoms of menopause. The combination of an enzyme producing probiotics such as $\beta$-glucosidase producing probiotics with soy extract help to improve the symptoms of menopause via producing bioactive isoflavone aglycones [47]. A study reported that the fermentation of soy milk with $L$. acidophilus does not significantly increase the absorption of Ca in osteopenic post-menopausal women [48]. Some controversial reports stated that the supplementation of soyisoflavone does not influence the microbiota of menopausal women [49]. The mechanism of probiotics mediated health improvement in menopausal women is not yet explained clearly. The connection between probiotic, gut microbiota, vaginal microbiota, and hormone (estrogen) deficit are the subject of several controversies. Further detailed well-planned intensive studies are required to explore the mysteries between the probiotics and menopause.

\section{ACKNOWLEDGMENT}

BSS and PK gratefully acknowledge the CMU Post-Doctoral Fellowship, and Faculty of Pharmacy, Chiang Mai University for the support. All the authors wish to thank CMU research grant for the necessary support.

\section{AUTHORS CONTRIBUTIONS}

BSS and PK contributed to conception and design, acquisition, manuscript preparation, and critical revision of the manuscript. CC involved in the review and finalization of the manuscript. All the authors agree with the content of the manuscript.

\section{CONFLICT OF INTERESTS}

The authors declare that there is no conflict of interests

\section{REFERENCES}

1. Schoenaker DAJM, Jackson CA, Rowlands JV, Mishra GD. Socioeconomic position, lifestyle factors, and age at natural menopause: a systematic review and meta-analyses of studies across six continents. Int J Epidemiol 2014;43:1542-62.
2. Monteiro NES, Queiros LD, Lopes DB, Pedro AO, Macedo GA. Impact of microbiota on the use and effects of isoflavones in the relief of climacteric symptoms in the menopausal women-a review. J Funct Foods 2018;41:100-11.

3. Gold EB. The timing of the age at which natural menopause occurs. Obstet Gynecol Clin North Am 2011;38:425-40.

4. Davis S. Menopause. Nat Rev Dis Primers 2015;1:15004.

5. Mohammed K, Moain A, Dabrh A, Benkhadra K, Nofal AA, Leon $\mathrm{BGC}$, et al. Oral vs transdermal estrogen therapy and vascular events: a systematic review and meta-analysis. J Clin Endocrinol Metab 2015;100:4012-20.

6. Roussouw JE, Anderson GL, Prentice RL, LaCroix AZ, Kooperberg C, Stefanick ML, et al. Risks and benefits of estrogen plus progestin in healthy post-menopausal women. JAMA 2002;288:321-33.

7. Beral V. Breast cancer and hormone-replacement therapy in a million women study. Lancet 2003;362:419-27.

8. Rozenberg S, Vandromme J, Antoine C. Postmenopausal hormone therapy: risks and benefits. Nat Rev Endocrinol 2013; 9:216-27.

9. Ensrud KE, Joffe H, Guthrie KA, Larson JC, Reed SD, Newton KM, et al. Effect of escitalopram on insomnia symptoms and subjective sleep quality in healthy perimenopausal and postmenopausal women with hot flashes: a randomized controlled trial. Menopause 2012;19:848-55.

10. Moreira AC, Silva AM, Santos MS, Sardao VA. Phytoestrogens as alternative hormone replacement therapy in menopause: what is real, what is unknown. J Steroid Biochem Mol Biol 2014; 143:61-71.

11. Sivamaruthi BS, Kesika P, Chaiyasut C. Probiotic based therapy for atopic dermatitis: outcomes of clinical studies. Asian Pac J Trop Biomed 2018;8:328-32.

12. Doron SI, Hibberd PL, Gorbach SL. Probiotics for the prevention of antibiotic-associated diarrhea. J Clin Gastroenterol 2008;42:S58-63.

13. Isolauri E, Rautava $S$, Salminen S. Probiotics in the development and treatment of allergic disease. Gastroenterol Clin North Am 2012;41:747-62.

14. Tomaro Duchesneau C, Saha S, Malhotra M, Jones ML, Labbe A, Rodes L, et al. Effect of orally administered L. fermentum NCIMB 5221 on markers of metabolic syndrome: an in vivo analysis using ZDF rats. Appl Microbiol Biotechnol 2014;98:115-26.

15. Dylag K, Hubalewska Mazgaj M, Surmiak M, Szmyd J, Brzozowski T. Probiotics in the mechanism of protection against gut inflammation and therapy of gastrointestinal disorders. Curr Pharm Des 2014;20:1149-55.

16. Di Gioia D, Aloisio I, Mazzola G, Biavati B. Bifidobacteria: their impact on gut microbiota composition and their applications as probiotics in infants. Appl Microbiol Biotechnol 2014;98:563-77.

17. Dib W, Chekroun A, El-Ghaish S, Choiset Y, Chobert J, Haertle T, et al. Effects of orally administered enterococcus faecium on the immune systemic response and intestinal epithelial 
structure in Balb/c mice immunized by bovine $\beta$-lactoglobulin. Int J Pharm Pharm Sci 2014;6:587-90.

18. Bharti V, Mehta A, Singh S, Jain N, Ahirwal L, Mehta S Bacteriocin: a novel approach for preservation of food. Int J Pharm Pharm Sci 2015; 7:20-9.

19. Demers M, Dagnault A, Desjardins JA. Randomized doubleblind controlled trial: Impact of probiotics on diarrhea in patients treated with pelvic radiation. Clin Nutr 2014;33:761-7.

20. Sirilun S, Sivamaruthi BS, Kumar N, Kesika P, Peerajan S, Chaiyasut C. Lactobacillus-fermented plant juice as a potential ingredient in cosmetics: formulation and assessment of natural mouthwash. Asian J Pharm Clin Res 2016;9(Suppl 3):52-6.

21. Sivamaruthi BS. A comprehensive review on clinical outcome of probiotic and synbiotic therapy for inflammatory bowel diseases. Asian Pac J Trop Biomed 2018;8:179-86.

22. Sivamaruthi BS, Chaiyasut C, Kesika P. Cosmeceutical importance of fermented plant extracts: a short review. Int J Appl Pharm 2018;10:31-4.

23. Sivamaruthi BS, Kesika P, Chaiyasut C. A review on anti-aging properties of probiotics. Int J Appl Pharm 2018;10:9-12.

24. Vieira AT, Castelo PM, Ribeiro DA, Ferreira CM. Influence of oral and gut microbiota in the health of menopausal women. Front Microbiol 2017;8:1884.

25. Borrelli F, Ernst E. Alternative and complementary therapies for the menopause. Maturitas 2010;66:333-43.

26. Ravel J, Gajer P, Abdo Z, Schneider GM, Koenig SS, McCulle SL, et al. Vaginal microbiome of reproductive-age women. Proc Natl Acad Sci USA 2011;108(Suppl 1):4680-7.

27. van de Wijgert JH, Borgdorff H, Verhelst R, Crucitti T, Francis $\mathrm{S}$, Verstraelen, et al. The vaginal microbiota: what have we learned after a decade of molecular characterization? PLoS One 2014;9:e105998.

28. Petrova MI, Lievens E, Malik S, Imholz N, Lebeer S. Lactobacillus species as biomarkers and agents that can promote various aspects of vaginal health. Front Physiol 2015;6:81.

29. Younes JA, Lievens E, Hummelen R, van der Westen R, Reid G Petrova MI. Women and their microbes: the unexpected friendship. Trends Microbiol 2018;26:16-32.

30. Hillier SL, Lau RJ. Vaginal microflora in postmenopausal women who have not received estrogen replacement therapy. Clin Infect Dis 1997;25(Suppl 2):S123-6.

31. Cauci S, Driussi S, De Santo D, Penacchioni P, Iannicelli $T$, Lanzafame $\mathrm{P}$, et al. Prevalence of bacterial vaginosis and vaginal flora changes in peri-and postmenopausal women. J Clin Microbiol 2002;40:2147-52.

32. Pabich WL, Fihn SD, Stamm WE, Scholes D, Boyko EJ, Gupta K Prevalence and determinants of vaginal flora alterations in postmenopausal women. J Infect Dis 2003;188:1054-8.

33. Srinivasan S, Liu C, Mitchell CM, Fiedler TL, Thomas KK, Agnew $\mathrm{KJ}$, et al. Temporal variability of human vaginal bacteria and relationship with bacterial vaginosis, PLoS One 2010;5:e10197.

34. Gajer P, Brotman RM, Bai G, Sakamoto J, Schutte UM, Zhong X, et al. Temporal dynamics of the human vaginal microbiota. Sci Transl Med 2012;4:132-52.

35. Martin DH. The microbiota of the vagina and its influence on women's health and disease. Am J Med Sci 2012;343:2-9.
36. Muhleisen AL, Herbst-Kralovetz MM. Menopause and the vaginal microbiome. Maturitas 2016;91:42-50.

37. Eschenbach DA, Thwin SS, Patton DL, Hooton TM, Stapleton AE, Agnew $\mathrm{K}$, et al. Influence of the normal menstrual cycle on vaginal tissue, discharge, and microflora. Clin Infect Dis 2000;30:901-7.

38. Mirmonsef P, Hotton AL, Gilbert D, Burgad D, Landay A, Weber $\mathrm{KM}$, et al. Free glycogen in vaginal fluids is associated with Lactobacillus colonization and low vaginal $\mathrm{pH}$. PLoS One 2014;9:e102467.

39. Petricevic L, Unger FM, Viernstein H, Kiss H. Randomized, double-blind, placebo-controlled study of oral lactobacilli to improve the vaginal flora of postmenopausal women. Eur J Obstet Gynecol Reprod Biol 2008;141:54-7.

40. Palacios S, Rojo Ial, Cancelo MJ, Neyro JL, Castelo-Branco C. Women's perception of the efficacy of a soy extract with probiotic: the M3 study. Gynecol Endocrinol 2008;24:178-83.

41. Jaisamrarn U, Triratanachat S, Chaikittisilpa S, Grob P, Prasauskas V, Taechakraichana N. Ultra-low-dose estriol and lactobacilli in the local treatment of postmenopausal vaginal atrophy. Climacteric 2013;16:347-55.

42. Britton RA, Irwin R, Quach D, Schaefer L, Zhang J, Lee T, et al. Probiotic L. reuteri treatment prevents bone loss in a menopausal ovariectomized mouse model. I Cell Physiol 2014;229:1822-30.

43. Trimarco V, Rozza F, Izzo R, De Leo V, Cappelli V, Riccardi C, et al. Effects of a new combination of nutraceuticals on postmenopausal symptoms and metabolic profile: a crossover, randomized, double-blind trial. Int J Womens Health 2016;8:581-7.

44. Lambert MNT, Thorup AC, Hansen ESS, Jeppesen PB. Combined red clover isoflavones and probiotics potently reduce menopausal vasomotor symptoms. PLoS One 2017;12:e0176590.

45. Marschalek J, Farr A, Marschalek ML, Domig KJ, Kneifel W, Singer CF, et al. Influence of orally administered probiotic Lactobacillus strains on vaginal microbiota in women with breast cancer during chemotherapy: a randomized placebocontrolled double-blinded pilot study. Breast Care (Basel) 2017;12:335-9.

46. Liong MT. Probiotics: a critical review of their potential role as antihypertensives, immune modulators, hypocholesterolemics, and perimenopausal treatments. Nutr Rev 2017;65:316-28.

47. Otieno DO, Ashton JF, Shah NP. Stability of $\beta$-glucosidase activity produced by Bifidobacterium and Lactobacillus spp. in fermented soy milk during processing and storage. J Food Sci 2005;70:M236-41.

48. Cheung AL, Wilcox G, Walker KZ, Shah NP, Strauss B, Ashton JF, et al. Fermentation of calcium-fortified soya milk does not appear to enhance acute calcium absorption in osteopenic post-menopausal women. Br J Nutr 2011;105:282-6.

49. Guadamuro L, Delgado S, Redruello B, Florez AB, Suarez A, Martinez-Camblor P, et al. Equol status and changes in fecal microbiota in menopausal women receiving long-term treatment for menopause symptoms with a soy-isoflavone concentrate. Front Microbiol 2015;6:777. 